\title{
A "Múmia" e o "Coronel": Recepção nas Redes Sociais de Marina Silva e Ciro Gomes ${ }^{1}$
}

\author{
Glauce Cunha \\ Comunicadora e produtora de TV. \\ Mestranda no Programa de Pós- \\ Graduação em Linguagens, Mídia e Arte \\ da PUC-Campinas. \\ E-mail: glaucec@yahoo.com.br.
}

\section{Juliana Doretto}

Jornalista. Doutora em Ciências da Comunicação pela Universidade Nova de Lisboa. Professora e pesquisadora no Programa de Pós-Graduação em Linguagens, Mídia e Arte (Limiar) da PUC-Campinas. Cofundadora da Recria (Rede de Pesquisa em Comunicação, Infâncias e Adolescências).

E-mail: jdoretto@gmail.com.

\footnotetext{
${ }^{1}$ Uma primeira versão deste trabalho foi apresentada no GT-5, Estudos de Gênero, Sexualidades e Corporalidades, da 9a edição do Coninter (Congresso Internacional Interdisciplinar em Sociais e Humanidades), realizada de modo virtual entre 17 e 19 de novembro de 2020.
}

Resumo: O objetivo deste artigo é compreender como Marina Silva é percebida por sua audiência nas redes sociais, enquanto figura pública e mulher negra de origem pobre, no cenário político brasileiro, dominado por homens brancos. Para isso, por meio de um estudo de recepção, levantaram-se os comentários de uma postagem sua no Twitter, no dia 22 de maio de 2020, a fim de os comparar a comentários de um post realizado no mesmo dia e na mesma rede social por Ciro Gomes. Analisá-la comparativamente a Ciro Gomes, um político de características semelhantes às dela (extensa vida pública, viés ideológico parecido, participação em eleições presidenciais), é uma forma de compreender como o gênero pode impactar ou não os discursos dos sujeitos que interagem com produções midiáticas de políticos brasileiros. Como resultados, percebe-se que Marina foi mais atacada do que Ciro, com destaque à sua aparência física.

Palavras-chave: gênero, recepção, Marina Silva, Ciro Gomes.

La "Momia" y el "Coronel": Recepción en las Redes Sociales de Marina Silva y Ciro Gomes

Resumen: El propósito de este artículo es entender cómo Marina Silva es percibida por su audiencia en las redes sociales, como figura pública y mujer negra de origen pobre, en el círculo político brasileño dominado por hombres blancos. Para eso, a partir de un estudio de recepción, comparamos los comentarios de una publicación de Marina en Twitter el 22 de mayo de 2020 con otros de una publicación realizada el mismo día y en la misma red social por Ciro Gomes. Analizarla con la de Ciro, un político de similares características (amplia vida pública, similar visión ideológica, participación en elecciones presidenciales), es una forma de entender cómo el género puede impactar el discurso de sujetos que interactúan con las producciones mediáticas de los políticos brasileños. Como resultado, Marina fue más atacada que Ciro con énfasis en su apariencia física.

Palabras clave: género, recepción, Marina Silva, Ciro Gomes.

The "Mummy" and the "Colonel": Reception of Marina Silva and Ciro Gomes on Social Networks

Abstract: This article aims to understand the way Marina Silva - a black woman of poor origin inserted within the Brazilian political scenario, which is dominated by white men is perceived by the online audience. This reception study compared the comments of two Twitter posts made on May 22, 2020 - one from Mariana Silva, and the other from Ciro Gomes. As Silva, Ciro has an extensive public life, similar ideologies, and also participated in presidential elections, so that analyzing this figure is a way of understanding how gender may impact the discourse of individuals interacting with media produced by Brazilian politicians. The results indicate that Marina Silva was more attacked than Ciro Gomes, especially regarding her physical appearance.

Keywords: genre, reception, Marina Silva, Ciro Gomes. 
${ }^{2}$ Dados colhidos em 26 de maio de 2020.

${ }^{3}$ A reunião tinha sido citada, pelo ex-ministro da Justiça Sérgio Moro, como um indício de que o presidente Jair Bolsonaro pretendia interferir na autonomia da Polícia Federal.

${ }^{4}$ https://www.youtube.com/ watch?v=BWDemNNMbeU.

${ }^{5}$ https://saude.abril.com.br/medicina/ oms-decreta-pandemia-do-novocoronavirus-saiba-o-que-isso-significa

${ }^{6} \mathrm{O}$ que dá maior relevância à informação é o fato de o presidente Jair Bolsonaro ser acusado constantemente de envolvimento com membros ativos dessas milícias, que operam como organizações criminosas em comunidades de baixa renda. Bolsonaro e sua família possuem um histórico de longa data de proximidade a membros dessas organizações.

${ }^{7}$ https://congressoemfoco.uol.com. br/governo/advogado-de-milicianose-nomeado-assessor-especial-doministro-da-saude/?aff_source $=56 \mathrm{~d} 955$ 33a8284936a374e3a6da3d7996.

${ }^{8}$ Dados colhidos em 6 de junho de 2020.
No dia 22 de maio de 2020, às 20h53, a ex-senadora Marina Silva publicou a seguinte mensagem, através de sua conta no Twitter: "Esperamos que Ministério Público Federal, STF e Congresso tomem medidas imediatas para o afastamento do ministro Ricardo Salles. Ao tramar dolosamente contra a própria pasta, demonstra agir com desvio de finalidade". A mensagem vinha acompanhada de um link do site Observatório do Clima, de que foi colhida a citação compartilhada por ela. Essa postagem gerou 324 comentários, 726 compartilhamentos e mais de 4,6 mil curtidas².

Nesse mesmo dia, o ministro Celso de Mello, do Supremo Tribunal Federal (STF), tinha acabado de autorizar a divulgação do vídeo da reunião ministerial feita no dia 22 de abril de $2020^{3}$. A gravação foi exibida praticamente em sua totalidade por diversos veículos de comunicação, causando grande reação pública por parte de diferentes instituições, de personalidades do meio político e artístico e do cidadão comum. A fala do ministro do Meio Ambiente, a que Marina faz referência em sua postagem, defende "passar a boiada" e "mudar regras", aproveitando o momento em que os meios de comunicação têm sua atenção voltada à pandemia de Covid-194.

No dia 11 de março, a Organização Mundial da Saúde (OMS) declarou ao mundo que vivemos uma pandemia: o diretor do órgão, Tedros Adhanom Ghebreyesus, comunicou que o número de casos de Covid-19 tinha aumentado 13 vezes fora da China, o país de origem da doença. O vírus já estava presente em 114 nações ${ }^{5}$. A partir desse dia, governos do mundo todo começaram a tomar medidas preventivas e a trabalhar em mecanismos de alertas e planos de contenção para que a contaminação pelo vírus fosse desacelerada. Diferentes normas e propostas começam a dividir a opinião pública mundial. Como preservar vidas e preservar a economia? Medidas nacionais começam a ser coordenadas pelo Ministério da Saúde juntamente com as normas dos governos estaduais. No entanto, iniciou-se aí um caminho de divergências no enfrentamento da Covid-19 entre o presidente Jair Bolsonaro e a maioria dos governadores de estados. A crise ideológica e política já existente se torna ainda mais profunda.

Nesse contexto, nesse mesmo dia 22 de maio de 2020, Ciro Gomes compartilhou seus posicionamentos através de seu perfil pessoal no Twitter, como também fez Marina Silva. Às 15h12, o político postou a seguinte mensagem: "Perderam completamente a vergonha na cara!" - uma exclamação sobre a notícia anexada à mensagem, veiculada pelo site Congresso em Foco, que trazia a seguinte chamada: "Advogado de milicianos ${ }^{6}$ é nomeado assessor especial do ministro da Saúde"7. Essa postagem gerou 263 comentários, 827 compartilhamentos e 5.880 curtidas $^{8}$.

O objetivo inicial desta pesquisa é compreender como Marina é percebida por sua audiência nas redes sociais, enquanto figura pública, mulher negra de origem pobre, no cenário político brasileiro dominado por homens brancos, a partir dessa postagem. Analisar Ciro, um político de características semelhantes às dela (extensa vida pública, viés ideológico parecido, participação em eleições presidenciais), mas que é seu contraponto como homem branco, é uma forma de compreender como o gênero pode impactar ou não os discursos dos sujeitos que interagem com produções midiáticas de políticos brasileiros. Para isso, adotaremos a perspectiva dos estudos de recepção das mensagens midiáticas, associada à análise de conteúdo. Porém, primeiramente, debateremos a presença das mulheres na política e a participação desses dois atores políticos nas redes sociais.

\section{Mulheres, Política e Mídia}

Castells (1999), ao falar sobre como trabalho e emprego foram transformados pelas mudanças tecnológicas, diz que esse processo não diminuiu o número de vagas de emprego como um todo, pois, apesar algumas categorias terem desaparecido, outras surgiram. Porém, a remuneração não acompanhou o aumento da produtividade e do lucro. Diante desse quadro, muitas mulheres entraram no mercado de trabalho para manter o padrão de vida de suas famílias. E, segundo o autor, "a feminização da força de trabalho afetou substancialmente as bases econômicas do patriarcado e abriu um caminho para a ascensão da consciência feminina" (Castells, 1999, p. VII). 
Essa abertura redefiniu alguns papéis sociais de gênero na sociedade, como quando a mulher passou a ser também provedora do sustento da família. Porém, os cargos de liderança e poder não refletem proporcionalmente a presença feminina no mercado de trabalho, inclusive na participação política. Um dos motivos para esse fato, segundo Finamore e Carvalho (2006, p. 353), seriam os estereótipos das funções que os gêneros devem cumprir em sociedade: "as mulheres candidatas a cargos eletivos têm de enfrentar o estereótipo que coloca os homens nos cargos de liderança política, reservando às mulheres o trato dos problemas domésticos".

No Brasil, é recente a chegada de mulheres ao poder político, especialmente se levarmos em consideração que aqui, até o início do século passado, o voto era um direito exclusivo dos homens. Na Suíça, um país de primeiro mundo, mulheres só puderam votar em 1971; na África do Sul, apenas em 1993; na Arábia Saudita, em 2011.

Em nosso país, a primeira eleitora foi Celina Guimarães, que em 1927, na cidade de Mossoró, RN, exerceu esse direito assegurado por uma lei de seu estado. Em seguida, apelou ao Senado Federal, via telegrama, para que essa garantia fosse estendida a todas as compatriotas: "Algumas fontes enfatizam que Celina não planejara ser a primeira eleitora e ficou surpresa com toda a repercussão que houve. Mas o fato é que a potiguar e o estado do Rio Grande do Norte entraram para a história..." (Schumaher \& Ceva, 2015, p. 73).

Isso só foi possível porque outra mulher, Bertha Lutz, em retorno ao Brasil depois de ter concluído seus estudos em Paris, em 1918, iniciou sua luta pelos direitos das mulheres, que incluíam o direito ao voto e o acesso à educação:

Desde que voltou ao Brasil, Bertha mergulhou na luta pelo sufrágio universal, que garantisse os direitos políticos das mulheres, ou seja, a sua participação nas eleições e na carreira pública. Outro tema de sua preocupação se referia à ampliação do acesso à educação, pois a maioria da população brasileira na época era analfabeta grande parte constituída de mulheres. (Schumaher \& Ceva, 2015, p. 67)

Embora tenha havido grandes avanços nesse sentido nas últimas décadas - dos quais o mais notável é a chegada de Dilma Rousseff ao cargo máximo do poder Executivo, em 2011 - , as estatísticas ainda apontam grande desigualdade. De acordo com matéria publicada em março de 2018 pelo jornal O Globo, dados divulgados pelo Instituto Brasileiro de Geografia e Estatística (IBGE), em seu estudo "Estatísticas de gêneroindicadores sociais das mulheres no Brasil", mostram que o país ocupa a 152a posição no ranking de representatividade feminina parlamentar, de um total de 192 países. Apenas 10,5\% do conjunto de deputados federais são mulheres (Pains, 2018).

Segundo Finamore e Carvalho (2006), "a mídia tem papel fundamental na disseminação das representações da realidade sócio-econômica e da imagem das mulheres, e dos políticos, influenciando a formação da opinião pública em diferentes circunstâncias, inclusive durante o processo eleitoral" (Finamore \& Carvalho, 2006, p. 359). Para eles, é preciso, pois, investigar os diferentes meios de comunicação pelos quais circulam esses discursos hegemônicos, que cristalizam os estereótipos de gênero, interferindo na percepção social sobre a participação política das mulheres.

Portanto, entender como a cultura de massa consolida o sujeito moderno, no sentido de compreender como ela produz e intensifica seus pensamentos e comportamentos (Morin, 1962), em relações aos padrões sociais estabelecidos, é caminho necessário para aprender sobre a importância e a urgência de aspirações ligadas à representatividade política feminina. Ou seja, na produção midiática de massa, podemos encontrar discursos com os quais nos identificamos e que nos permitem expressar nossos desejos, frustrações e realizações em relação aos papéis sociais de gênero.

A cultura de massa se constituiu em função das necessidades individuais que emergem. Ela vai fornecer à vida privada as imagens e os modelos que dão forma às suas aspirações. Algumas dessas aspirações não podem se satisfazer nas grandes cidades civilizadas, burocratizadas; nesse caso a cultura resgata 
uma evasão por procuração em direção a um universo onde reinam a aventura, o movimento, a ação sem freio, a liberdade, não a liberdade no sentido político do termo, mas a liberdade no sentido individual, afetivo, íntimo, da realização das necessidades ou instintos inibidos ou proibidos. (Morin, 1962, p. 90)

Essa liberdade, a realização desses instintos inibidos, encontra lugar ainda mais confortável nos novos meios de comunicação existentes hoje, como as redes sociais? Han (2017) avalia que sim. O sujeito contemporâneo - que ele chama como aquele "de desempenho", classificado como alguém de positividade excessiva, que se autoestafa em busca de atingir ideais de produtividade e performance (estimulados pela ideologia neoliberal) - é um indivíduo aparentemente livre, mas que, de fato, é escravo de si e desconfia do outro, com quem compete. Nesse sentido, o autor diz que vivemos num mundo carente de alteridade, que em nada nos compele a exercitar nosso pensamento sobre o diferente, algo que empobrece as relações humanas. Nesse contexto, as redes sociais, novos canais de comunicação que surgem com a promessa de fortalecer a diversidade cultural, acabam tomando sentido oposto, fortalecendo nossa resistência ao outro e nossos estereótipos. Mesmo que tenha a totalidade de um mundo virtual a ser explorado, o sujeito se conforma a ficar em um mesmo lugar, e os algoritmos ainda conspiram para que ele veja apenas o que lhe agrada.

O sujeito de desempenho esgotado, depressivo está, de certo modo, desgastado consigo mesmo. Está cansado, esgotado de si mesmo, de lutar consigo mesmo. Totalmente incapaz de sair de si, estar lá fora, de confiar no outro, no mundo, fica se remoendo, o que paradoxalmente acaba levando à autoerosão e ao esvaziamento. [...] Também os novos meios de comunicação e as técnicas de comunicação estão destruindo cada vez mais a relação com o outro. O mundo digital é pobre em alteridade e em sua resistência. (Han, 2017, p. 91)

A seguir, veremos como Marina Silva e Ciro Gomes se apropriam de suas mídias sociais e como os discursos que por ali circulam podem ser analisados sob a perspectiva dos estudos de recepção.

\section{Metodologia}

Depois de ter ocupado cargos públicos importantes, como os de senadora e ministra do Meio Ambiente, Marina Silva ganhou maior projeção e destaque no cenário da política nacional ao participar de três processos eleitorais para

${ }^{9} \mathrm{https}: / /$ politica.estadao.com.br/ noticias/geral,pv-lanca-marina-silvacomo-candidata-a-presidencia-nestaquinta-feira, 564037.

${ }^{10} \mathrm{https}: / /$ www1.folha.uol.com.br/fsp/ brasil/fc1602201008.html.

${ }^{11}$ Artigo escrito e publicado por Caio Túlio Costa, jornalista, doutor em Ciências da Comunicação pela USP, professor de jornalismo e consultor em novas mídias. Foi o coordenador de Mídia Digital da campanha de Marina Silva à Presidência em 2010 e é um dos sócios da MVL Comunicações, empresa responsável pela comunicação da candidatura. http://www.observatoriodaimprensa. com.br/e-noticias/o-papel-da-internetna-conquista-de-votos. a Presidência da República.

Seu perfil no Twitter foi criado em janeiro de 2010, ano em que se lançou pela primeira vez como candidata à Presidência do Brasil. Sua candidatura, que até então era apenas especulada, foi oficializada em junho de $2010^{\circ}$. Nessas eleições, a exministra do Meio Ambiente saiu na frente dos demais concorrentes ao ingressar nas mídias sociais, com estratégia própria para os meios digitais ${ }^{10}$. Com pouco espaço na propaganda eleitoral na TV e no rádio e poucos recursos advindos do Partido Verde (PV), Marina obteve 19.636.359 votos, resultado que a posicionou em terceiro lugar e qualificou a terceira colocação com maior percentual de votos $(19,33 \%)$ desde a primeira eleição democrática pós-ditadura. Assim, mostrou o potencial da internet, até então pouco explorado ${ }^{11} \mathrm{em}$ processos eleitorais.

Ciro Gomes nasceu no interior de São Paulo e, aos 4 anos, sua família mudou-se para o Ceará. Entrou na política nos anos 80, tornando-se um dos principais nomes políticos do estado. Como Marina, Ciro já participou de três processos eleitorais para a Presidência da República. Em sua última participação, em 2018, mesmo derrotado, antecipou o anúncio de que concorrerá nas eleições presidenciais de 2022. Desde então, vem realizando um trabalho de oposição ao governo Jair Bolsonaro, através de entrevistas concedidas a diversos veículos midiáticos e de postagens em suas redes sociais. Seu ingresso no Twitter aconteceu em abril de 2009, nove meses antes da entrada de Marina Silva. 
${ }^{12}$ Números coletados no dia 15 de junho de 2020.

\begin{tabular}{l|c|c}
\multicolumn{1}{c|}{ Redes sociais } & Marina Silva & Ciro Gomes \\
\hline TWITTER & 2.086 .717 & 1.020 .347 \\
\hline FACEBOOK & 2.336 .889 & 814.569 \\
\hline INSTAGRAM & 216.000 & 1.000 .000 \\
\hline YOUTUBE & 18.600 & 210.000 \\
\hline Total $^{12}$ & 4.658 .206 & 3.044 .916 \\
\hline
\end{tabular}

Tabela 1: Seguidores de Marina Silva e Ciro Gomes nas redes sociais Nota: Elaboração das autoras.

Vemos que, no valor total, Marina tem vantagem com relação a Ciro, com diferença de mais de um milhão de seguidores, e que tem mais que o dobro de Ciro em suas contas no Twitter e no Facebook. Contudo, é importante perceber que Ciro possui quase cinco vezes mais seguidores no Instagram e quase 12 vezes mais em seu canal de YouTube do que Marina. Tanto Instagram como YouTube são redes sociais mais imagéticas; portanto, a escolha do Twitter neste estudo é relevante por ser uma rede social que valoriza o conteúdo escrito, ainda que ofereça recursos para postagens de vídeos e imagens.

Para a realização desta pesquisa, recolhemos todos os comentários gerados pelas postagens de Marina e Ciro citadas acima. A coleta de mensagens referentes ao post de Marina foi feita manualmente no dia 26 de maio de 2020. Foram desconsiderados os comentários direcionados a terceiros, isto é, que não estavam nominados diretamente a ela. Além disso, mensagens incompreensíveis contendo representações gráficas (emojis, GIFs), capturas de telas e links também foram descartadas, restando 174 comentários para serem analisados. A coleta referente à postagem de Ciro foi feita manualmente no dia 6 de junho de 2020. A mesma regra de descarte dos comentários à postagem de Marina foi aplicada, restando 150 comentários a serem analisados. Não verificamos aqui marcações de gênero ou região dos comentaristas, em razão do escopo do trabalho.

Vale destacar que, em nossa análise mais geral das duas redes sociais, as postagens mais contundentes, nas quais Marina ou Ciro atacam com mais veemência o presidente Bolsonaro, são as que trazem o maior número de comentários e mais agressividade da parte dos comentaristas. As duas missivas analisadas aqui refletem esse caráter mais genérico.

Em seguida, a partir da leitura do material, os comentários foram categorizados de acordo com os temas e subtemas que se destacaram quanto à frequência. Seguiuse, portanto, uma das vertentes da análise de conteúdo, a chamada de "categorial": "é o método das categorias, espécie de gavetas ou rubricas significativas que permitem a classificação dos elementos de significação constitutivos da mensagem" (Bardin, 2002, p. 39).

Como dito, neste trabalho, queremos investigar comparativamente como os sujeitos compreendem as mensagens midiáticas produzidas por duas figuras importantes do cenário político brasileiro, mas de gêneros diferentes, pela perspectiva dos estudos de recepção. Essa linha guiou nossa categorização, exposta acima. Para Sousa (1994), as análises com esse viés enfrentam dificuldade por estarem ligadas à prática acadêmica original que as relaciona aos estudos de consumo, opinião pública, publicidade e marketing. Nesses estudos, no entanto, o sujeito não é visto apenas como um depósito, alvo de uma estratégia comunicacional traçada como ferramental, mas como alguém que pensa sobre o que consome.

Ou seja, é preciso tentar entender como ele se apropria das mensagens midiáticas: se dá novos significados a elas, apenas corrobora e amplia os significados já estabelecidos na sociedade, ou se as rejeita (Hall, 2003). Sobre isso, Canclini (2004) nos acrescenta que essa vertente crítica está ainda ligada à condição de circulação dos diferentes discursos, que é contingenciada pelas lógicas de produção da indústria capitalista, regentes dos meios de comunicação hegemônicos (e das redes sociais também). Em outras palavras: as narrativas circulantes no cenário midiático são circunstanciadas pelos modos de funcionamento da indústria cultural, cenário que possibilita que certas significações de oposição (que fazem frente a determinados 
${ }^{13}$ Texto original em espanhol: "Pero ¿es el sujeto solamente una construcción ficcional de los medios, o puede haber también sujetos críticos, espectadores que ejerzan iniciativas propias a pesar de las astutas manipulaciones mediáticas? Los estudios sobre el lado activo de la recepción demuestran que no hay medios omnipresentes, ni audiencias pasivas, pero la concentración monopólica y transnacional de las industrias de la cultura y la debilidad de las asociaciones de televidentes y consumidores dejan aún irresuelta la cuestión de cuánto nos permite ser sujetos el capitalismo de redes globalizadas. La posibilidad de serlo aparece no solo como la capacidad creativa y reactiva de los individuos; depende también de derechos colectivos y controles sociales sobre la producción y circulación de informaciones y entretenimento." estereótipos de gênero, no caso em tela) ocorram de forma relevante ou não. Aqui, como afirma Han (2017), devemos considerar a aversão à alteridade que sustenta o modo de funcionamento das redes sociais, cujos algoritmos destinam mensagens a usuários que tendem a concordar com elas:

Será que o assunto é apenas uma construção fictícia da mídia, ou também pode haver sujeitos críticos, espectadores que exercem suas próprias iniciativas, apesar das manipulações astutas da mídia? Estudos sobre o lado ativo da recepção mostram que não há mídia onipresente, audiências passivas, mas a concentração monopolista e transnacional das indústrias culturais e a fraqueza das associações de televisão e de consumidores ainda deixam a questão de quanto o capitalismo de redes globalizadas nos permite ser sujeitos. A possibilidade de sê-lo aparece não apenas como a capacidade criativa e reativa dos indivíduos; também depende de direitos coletivos e controles sociais sobre a produção e circulação de informações e entretenimento ${ }^{13}$. (Canclini, 2004, p. 148)

Por fim, em outro trabalho (Furtado \& Doretto, 2019), já advogamos que os estudos de recepção se caracterizam pela análise dos sentidos construídos pelos sujeitos no circuito da produção-consumo. Assim, a investigação dos comentários coletados nas redes sociais pode ser também uma forma de compreender os significados que se estabelecem no consumo das mensagens midiáticas, a partir de compreensões macrossociais sobre os temas debatidos nas missivas e investigações dos cenários que envolvem a publicação dessas mensagens, como fizemos nesta seção. Como dizem Cogo e Brignol (2011), as redes sociais podem ser um caminho para identificar construções de significados que reforçam o estabelecimento de vínculos entre os sujeitos ali presentes:

Entendemos que é pertinente aos pesquisadores da recepção refletir sobre a internet em suas múltiplas dimensões. Ou seja, partindo da sua concepção como um ambiente comunicacional que permite a produção, circulação e troca de conteúdos e informações, a aproximação entre diferentes formatos e lógicas de mídias, a interação interpessoal e o diálogo, o estabelecimento de vínculos, a construção de projeções das identidades de seus usuários, a configuração de uma memória compartilhada e o estabelecimento de lógicas colaborativas. (Cogo \& Brignol, 2011, p. 88)

Por fim, Flaz (1992, p. 218 apud Escosteguy, 2002) diz que os estudos de recepção devem problematizar o gênero para além das diferentes biológicas, de forma a entender como essas concepções "são constituídas e experimentadas e como nós pensamos ou, igualmente importante, não pensamos sobre elas". Neste trabalho, voltamos nosso olhar ao processo de construção de gênero e às resistências e críticas aos estereótipos que o envolvem.

Em seguida, passaremos a descrever os dados obtidos na análise dos comentários selecionados, buscando compreender como o exposto aqui se articula aos discursos coletados.

\section{Resultados Alcançados}

Como dito acima, as postagens de Marina e Ciro escolhidas para a análise neste artigo ocorreram na mesma data (22 de maio de 2020), apresentam conteúdo semelhante (em que ambos criticam ministérios do atual presidente Jair Bolsonaro) e têm números de interações próximos. Abaixo, seguem duas capturas de tela das respectivas mensagens de Marina Silva e Ciro Gomes: 


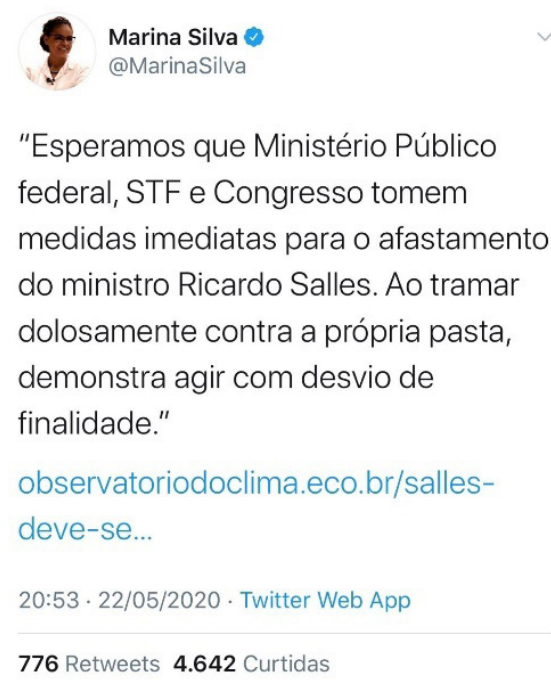

Figura 1: Postagem de Marina Silva no Twitter, no dia 22 de maio Fonte: Reprodução/Twitter

Ciro Gomes @cirogom... 22/05/2020
Perderam completamente a vergonha na cara!

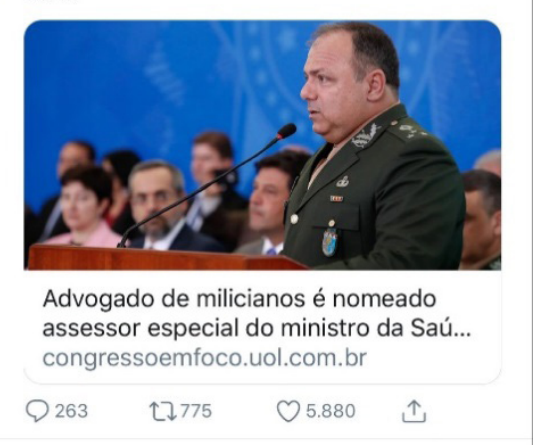

Figura 2: Postagem de Ciro Gomes no Twitter, no dia 22 de maio Fonte: Reprodução/Twitter.

Numa primeira etapa de análise, para os comentários às postagens dos dois políticos, foram criadas inicialmente duas categorias, que se destacam na primeira leitura do material: "desfavorável" e "favorável" à mensagem postada. Na categoria "desfavorável", surgiram 7 principais pontos de destaque (ou subcategorias) e, na "favorável", dois temas principais surgiram. É importante destacar que em um mesmo comentário pode haver mais de um tópico classificatório; isto é, os temas não se excluem mutuamente, mas se somam. Portanto, o número total de menções classificadas ultrapassa o número de comentários analisados.

Passemos a seguir à análise das manifestações encontradas na mensagem de Marina.

\section{Comentários nas postagens de Marina Silva}

Na tabela 2, apresentamos os 7 principais pontos de destaque desfavoráveis à postagem de Marina Silva, que foram classificados da seguinte maneira: 


\begin{tabular}{|c|c|c|}
\hline Subcategoria & Descrição do conteúdo & Quantidade \\
\hline Defesa de Bolsonaro & $\begin{array}{l}\text { Comentários de apoio ao presidente } \\
\text { Jair Bolsonaro e/ou ao ministro do } \\
\text { Meio Ambiente, Ricardo Salles, que } \\
\text { implicitamente são desfavoráveis a Marina. }\end{array}$ & 37 \\
\hline Caráter & $\begin{array}{l}\text { Comentários contendo ofensas e } \\
\text { xingamentos que colocam em questão } \\
\text { o seu caráter e sua capacidade intelectual, } \\
\text { como "cretina", "estúpida" e pedidos de } \\
\text { "cala boca". }\end{array}$ & 30 \\
\hline Desaparecimento & $\begin{array}{l}\text { Comentários que insinuam um sumiço da } \\
\text { parte de Marina Silva ou um aparecimento } \\
\text { apenas em ocasiões desfavoráveis aos } \\
\text { seus "inimigos" políticos (quem aparece } \\
\text { é porque estava supostamente sumido), } \\
\text { e, do mesmo modo, mensagens em que } \\
\text { o interlocutor sugere que ela volte a um } \\
\text { estado de desaparecimento. }\end{array}$ & 28 \\
\hline Atuação política & $\begin{array}{l}\text { Comentários contendo palavras ligadas } \\
\text { historicamente a questões políticas } \\
\text { e ofensas direcionadas a sua gestão } \\
\text { ou papel político, como "comunista", } \\
\text { "corrupta" e "incompetente". }\end{array}$ & 19 \\
\hline Aparência & $\begin{array}{l}\text { Comentários que continham substantivos } \\
\text { e adjetivos que sugerem, direta ou } \\
\text { indiretamente, ligação com sua aparência } \\
\text { supostamente grotesca, disforme ou } \\
\text { enrugada, num sentido pejorativo, sendo } \\
\text { as palavras "tartaruga" e "dinossauro" } \\
\text { as mais presentes, seguidas de "ET" (ser } \\
\text { extraterrestre). Há muitas menções feitas } \\
\text { por representações gráficas (emojis), o que } \\
\text { reforça o caráter de aparência. }\end{array}$ & 18 \\
\hline $\begin{array}{l}\text { Aspecto assustador e } \\
\text { raciocínio vagaroso }\end{array}$ & $\begin{array}{l}\text { Comentários que a adjetivam por meio do } \\
\text { substantivo "múmia". Essas mensagens não } \\
\text { se enquadram na categoria "Aparência" pelo } \\
\text { entendimento de que múmia, além de um } \\
\text { cadáver preservado, mirrado, esquelético e } \\
\text { magro, evoca algo assustador. E, no sentido } \\
\text { coloquial, é termo bastante usado também } \\
\text { quando queremos dizer que o sujeito é } \\
\text { alguém lerdo, de raciocínio vagaroso. }\end{array}$ & 9 \\
\hline Idade & $\begin{array}{l}\text { Comentários contendo o substantivo "velha", } \\
\text { usados numa conjuntura desdenhosa. }\end{array}$ & 4 \\
\hline Total & & 145 \\
\hline
\end{tabular}

Tabela 2: Comentários negativos na postagem de Marina Silva Nota: Elaboração das autoras.

Na categoria "favorável" à mensagem postada de Marina, dois principais temas apareceram: 


\begin{tabular}{l|l|c} 
Subcategoria & \multicolumn{1}{|c|}{ Descrição do conteúdo } & Quantidade \\
\hline $\begin{array}{l}\text { Oposição a } \\
\text { Bolsonaro }\end{array}$ & $\begin{array}{l}\text { Desaprovação e crítica de diferentes formas ao } \\
\text { presidente Bolsonaro e/ou ao ministro Salles, } \\
\text { do Meio Ambiente, ou desaprovação à agenda } \\
\text { política da atual gestão da Presidência. }\end{array}$ & 61 \\
\hline Competência & $\begin{array}{l}\text { Adjetivos elogiosos ligados à competência, à } \\
\text { liderança ou ao desempenho de Marina Silva. }\end{array}$ & 5 \\
\hline Total & & 66 \\
\hline
\end{tabular}

Tabela 3: Comentários positivos na postagem de Marina Silva

Nota: Elaboração das autoras.

Alguns comentários precisam ser destacados para demonstrar os pontos desta análise, sobretudo os que atacam essa figura pública, já que revelam várias nuances em como ela é compreendida pela sociedade. Temos aqui cinco exemplos que sugerem o sumiço da parte de Marina, como "hibernar", "voltar para a tumba" e alguns, que aparecerão posteriormente, dizem "volte para o casco, tartaruga". É interessante notar a evidência dessa ideia do sumiço, da invisibilidade de Marina, que está presente nas mensagens de vários sujeitos (quase $20 \%$ dos comentários negativos), tendo em vista que ela foi candidata nas últimas três eleições, tem concedido entrevistas constantes a diversos veículos e, sobretudo, ainda que sua presença nos principais veículos de comunicação fosse inconstante ou inexpressiva, em sua rede social, ela tem frequência diária de postagens:

Volte a hibernar....2022 está a 2 anos ainda!!! (Classificação “Desaparecimento", comentário, 22 maio 2020).

Silêncio. Só pode falar em 2022, lembra? (Classificação "Caráter" e "Desaparecimento", comentário, 22 maio 2020).

Volta pra tumba de onde nunca mais deveria sair... (Classificação "Aspecto assustador e raciocínio vagaroso" e "Desaparecimento", comentário, 22 maio 2020).

Volta pra tumba, Múmia! \#BolsonaroReeleito (Classificação "Aspecto assustador e raciocínio vagaroso" e "Defesa de Bolsonaro", comentário, 22 maio 2020).

${ }^{14}$ Respeitou-se a grafia original das mensagens.

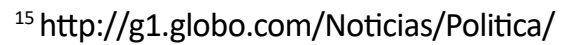
0,,MUL1272525-5601,00-MARINA+SILVA+ ANUNCIA+SAIDA+DO+PT+E+DEVE+SE+ FILIAR+AO+PV.html.

\footnotetext{
${ }^{16}$ https://piaui.folha.uol.com.br/ lupa/2018/11/09/verificamosmarina-desmatamento.
}

Aparecei a fantasminha. Vao catar. Babaçu (Classificação “Desaparecimento" e "Caráter", comentário 22 maio 2020) ${ }^{14}$.

Nos três comentários a seguir, aparecem palavras que se referem a questões políticas ligadas à ideologia de esquerda e que os integram às categorias de "Atuação política" ou de "Defesa de Bolsonaro". No primeiro deles, o interlocutor a chama de "guerrilheira midiática", e a palavra "guerrilheira" aqui usada parece fazer referência a quem está disposto a agir em prol de uma ideologia através do uso de armas. $O$ autor dessa mesma mensagem sugere uma mudança de comportamento em seu histórico, de "doce" a "guerrilheira". Em seu histórico, porém, manteve-se a luta pelos ideais socioambientais, o que pode sugerir que talvez a mudança tenha acontecido na compreensão do interlocutor.

No segundo comentário fica evidente que ainda hoje Marina tem sua imagem fortemente ligada ao ex-presidente Lula, mesmo que tenha rompido politicamente com ele e com o Partido dos Trabalhadores (PT) em $2009^{15}$. Foi ainda forte concorrente de Dilma Rousseff nas eleições de 2014 e atuou como opositora política ao PT. Mas o partido parece ainda ser, para alguns missivistas, a única legenda relacionada às esquerdas no país.

No terceiro comentário, o interlocutor sugere que o interesse de Marina pelas questões ambientais está ligado à corrupção, além de afirmar que seu marido é condenado por desmatamento. De fato, seu esposo, Fabio Vaz de Lima, foi acusado de ter cometido esse crime, mas nunca foi condenado. Alguns veículos noticiaram que há inúmeras fake news ligando o nome de Fabio ao fato e que não existe comprovação dessas acusações ${ }^{16}$. Os comentários são esses: 
Marina, deu! Chega! Acabou! Todo mundo sabe. O BRASIL apoia o que eles disseram naquela reunião! Lamentável uma pessoa tão doce ter se tornado uma GUERRILHEIRA MIDIÁTICA. É muito triste! Depois de velha cair numa valha dessa. Reaja! (Classificação "Idade", "Atuação política" e "Defesa de Bolsonaro", comentário, 22 maio 2020).

Não cuidou nem do Acre quando teve oportunidade, tudo capacho do Lula (Classificação "Atuação política”, comentário, 23 maio 2020).

Marina e seu desejo perturbado do meio ambiente. Mesmo seu marido ou ex ser condenado por desmatamento ela insiste nessa pasta. Algo de muito bom lá deve ter. Ela não quer largar o osso. (Classificação "Atuação política", comentário, 23 maio 2020).

Há ainda muitos comentários que reúnem três ou mais categorias, dos quais destacamos abaixo um que reuniu cinco. Aqui, além de ser acusada de gestora incompetente, Marina é chamada de "múmia" (que carrega alguns sentidos já definidos por este estudo, na Tabela 1), de "extraterrestre" (que remete à aparência), e de "insignificante", que aqui aparece como uma ofensa, já que remete a alguém que não possui significado. Além disso, o comentário sugere o desaparecimento de Marina (ao pedir sua volta ao sarcófago) e reitera o apoio a Bolsonaro.

O ET esqueceu que o desmatamento em sua gestão o maior nos últimos 25 anos. Se tranque no sarcófago insignificante. \#BolsonaroReeleito (Classificação "Aparência", "Atuação política", "Aspecto assustador e raciocínio vagaroso", "Caráter" e "Defesa de Bolsonaro", comentário, 22 maio 2020).

Os cinco próximos comentários têm em comum ataques ligados à aparência, que aparecem em 15\% do total das mensagens (nas categorias "Aparência", "Aspecto assustador e raciocínio vagaroso" e "Idade"). Muitas das mensagens possuem representações gráficas (emojis) de tartarugas e dinossauros. É comum répteis serem descritos como animais repugnantes (assim como anfíbios e alguns insetos) e, nesse caso, têm em comum um aspecto rugoso, elemento estético que evoca feiura e envelhecimento, no sentido pejorativo. Algumas menções referem-se a ela como "Curupira", personagem do folclore brasileiro que protege as florestas e os animais:

Sai Dinossauro (Classificação “Aparência”, comentário, 22 mai. 2020).

Pronto, o Currupira saiu da mata. (Classificação "Aparência", comentário, 22 maio 2020).

Soltaram mais cedo hj kkkkk (em referência a emojis de ET acrescentados à mensagem) (Classificação “Aparência”, comentário, 22 maio 2020).

Afff tartaruga... Volta pro casco (Classificação "Aparência" e "Desaparecimento", comentário, 22 maio 2020).

${ }^{17}$ Marina Silva foi nomeada ministra do Meio Ambiente em 2003, pelo então presidente Lula. Por seu trabalho na área, é reconhecida através de prêmios internacionais, tendo recebido em 2007 a maior condecoração das Nações Unidas, o Champions of the Earth, em reconhecimento ao seu trabalho. Através de seu posicionamento contrário à fala de Ricardo Salles, a ex-ministra do Meio Ambiente quer ressaltar a incongruência de uma agenda que não trabalha em favor das causas ambientais. Declarações suas como essa têm sido habituais, em oposição à gestão do atual governo de Jair Bolsonaro. Vai dormir tartaruga (Classificação "Aparência" e "Caráter", comentário,
22 maio 2020).

Marina de fato tem um longo histórico de lutas socioambientais ${ }^{17}$; portanto, seria natural essa relação. Porém, as associações feitas, assim como a que a liga à figura de extraterrestres, parecem sugerir uma descrição ofensiva, ligada, mais uma vez, à aparência física. Ambos os seres (ETs e Curupira) têm aparência corpórea disforme, em relação às proporções mais comuns do corpo humano.

\section{Comentários nas postagens de Ciro Gomes}

Abaixo, apresentamos os 7 principais tópicos de destaque (subcategorias) desfavoráveis a Ciro. 


\begin{tabular}{|c|c|c|}
\hline Categoria & Descrição do conteúdo & Quantidade \\
\hline $\begin{array}{l}\text { Atuação } \\
\text { política }\end{array}$ & $\begin{array}{l}\text { Comentários sobre possíveis relações com o PT, ou } \\
\text { críticas ao partido, e questionamentos a respeito de } \\
\text { sua competência como gestor, bem como acusações } \\
\text { de corrupção. }\end{array}$ & 14 \\
\hline $\begin{array}{l}\text { Defesa de } \\
\text { Bolsonaro } \\
\end{array}$ & Apoio a Bolsonaro, que seria uma crítica indireta a Ciro. & 10 \\
\hline $\begin{array}{l}\text { Ofício do } \\
\text { advogado }\end{array}$ & $\begin{array}{l}\text { Comentários que afirmam que a ética da advocacia } \\
\text { obriga esses profissionais a prestar seus serviços } \\
\text { a qualquer cidadão (tendo em vista que a notícia } \\
\text { postada por Ciro sugere que um advogado de miliciano } \\
\text { não é uma boa escolha para um cargo público). }\end{array}$ & 10 \\
\hline Caráter & $\begin{array}{l}\text { Comentários contendo ofensas e xingamentos } \\
\text { que colocam em questão o seu caráter, como } \\
\text { a expressão "vagabundo". }\end{array}$ & 7 \\
\hline Cobrança & Cobrança de ação da parte de Ciro. & 3 \\
\hline Origem & $\begin{array}{l}\text { Comentários relacionados à origem nordestina do } \\
\text { político, como "coronel" e "cangaciro", apelido que } \\
\text { faz um trocadilho com a palavra "cangaceiro" e seu } \\
\text { nome, "Ciro". }\end{array}$ & 3 \\
\hline Alcoolismo & $\begin{array}{l}\text { Menções que fazem referência ao consumo de álcool } \\
\text { por Ciro Gomes. }\end{array}$ & 1 \\
\hline Total & & 48 \\
\hline
\end{tabular}

Tabela 4: Comentários negativos na postagem de Ciro Gomes

Nota: Elaboração das autoras.

Na categoria "favorável" à mensagem postada de Ciro, surgiram dois principais temas:

\begin{tabular}{|l|l|l|}
\hline \multicolumn{1}{|c|}{ Categoria } & \multicolumn{1}{|c|}{ Descrição do conteúdo } & Quantidade \\
\hline $\begin{array}{l}\text { Oposição } \\
\text { a Bolsonaro }\end{array}$ & $\begin{array}{l}\text { Total concordância com a crítica feita e } \\
\text { desaprovação do governo ou do presidente } \\
\text { Bolsonaro e/ou desaprovação às táticas adotadas } \\
\text { pelo ministro interino da Saúde. }\end{array}$ & 108 \\
\hline Competência & $\begin{array}{l}\text { Adjetivos elogiosos ligados à competência, à } \\
\text { liderança ou ao desempenho de Ciro Gomes. }\end{array}$ & 5 \\
\hline Total & & 113 \\
\hline
\end{tabular}

Tabela 5: Comentários positivos na postagem de Ciro Gomes

Nota: Elaboração das autoras.

${ }^{18} \mathrm{O}$ coronelismo é um brasileirismo usado para definir uma estrutura de poder que teve início no período regencial, em que os grandes proprietários recebiam a patente de coronel, se utilizavam das forças policiais para a manutenção da ordem e tinham nessas milícias o apoio para execução de seus próprios interesses. O cangaceiro era o homem que fazia parte de um bando armado. $O$ cangaço foi um movimento social disseminado no sertão nordestino entre os séculos 19 e 20. Havia vários grupos distintos, mas todos alinhados com banditismo e inimizade com o Estado. Cangaceiros eram inimigos dos coronéis, que eram opressores dos mais pobres e desfavorecidos.

Assim como tratamos os comentários no post de Marina, trazemos pontos de destaque dos comentários ao post de Ciro. Apresentamos aqui os três únicos exemplos cujo conteúdo é pejorativo, por referenciarem a origem nordestina de Ciro Gomes por meio de expressões como "coronel" e "cangaciro" (em que há o trocadilho da palavra "cangaceiro" com seu nome). Os dois termos fazem parte do imaginário e dos estereótipos ligados ao Nordeste. O interessante é que essas duas figuras da região estão presentes, teoricamente, em lados opostos. O coronel era a figura que explorava os mais pobres em favor de seus próprios interesses, enquanto o cangaceiro era alguém que fazia parte de um movimento social contra o Estado, isto é, contra o próprio coronelismo, tão presente na estrutura social da época. Entretanto, ambos são figuras ligadas à violência e ao poder ${ }^{18}$ :

CangaCiro! (Classificação “Origem”, comentário, 22 maio 2020).

CANGACIRO RETROESCAVADEIRA (Classificação “Origem”, comentário, 22 maio 2020).

Coroné do pé rachado está pedindo processo, mais um dos vários (Classificação "Origem" e "Caráter", comentário, 22 maio 2020). 
Os próximos comentários têm em comum referências ao PT e à ligação com esquemas de corrupção, além de questionarem as indicações do partido a alguns cargos do STF. São missivas que aparecem com destaque no corpus analisado. É evidente que o interlocutor associa a imagem de Ciro Gomes ao PT, por ter sido ministro do governo Lula (de 2003 a 2006) ou pela associação desse político a partidos de esquerda e de centro-esquerda, dos quais Ciro fez e faz parte. Outra análise é que, na percepção do comentador, a crítica de Ciro Gomes é seletiva:

Palavrões que não foram ouvidos na reunião ministerial: "propina" "Caixa 2", "Superfaturamente" "Triplex" "Amante" "Foro de São Paulo" "Pasadena" "Petrolão" "Mariel” "Odebrecht" \#BolsonaroReeleito (Classificação "Atuação política" e "Defesa de Bolsonaro", comentário, 23 maio 2020).

Advogado do PT é nomeado ministro do STF. (Classificação "Atuação política", comentário, 22 maio 2020).

Cirão dê uma olhada no passado de alguns ministros do STF vai ficar chocado. (Classificação “Atuação política”, comentário, 22 maio 2020).

Realmente o senhor deveria ir para o STF Sr Ciro. És m guardião dos bons costumes! Bolsonardo vai ganhar novamente em 2022. Em 2026 ele escolhe outro para ganhar! (Classificação "Atuação política" e "Defesa de Bolsonaro", comentário, 22 maio 2020).

Por fim, transcrevem-se abaixo alguns dos comentários favoráveis à postagem, mais presentes aqui do que na publicação de Marina. Isso aponta que, por alguma razão, o papel de oposição que Ciro Gomes ocupa é mais aceito entre seus interlocutores, se compararmos os comentários de seu post aos de Marina Silva.

Em um deles, o interlocutor, apesar de não concordar com a crítica feita na mensagem ao ponderar sobre o ofício do advogado, se refere a Ciro como "presidente", demonstrando a sua escolha como eleitor. No segundo exemplo de comentário favorável, o sujeito interage em concordância com a crítica do tuíte, mencionando que, desde a reeleição de Dilma Rousseff (PT), o país se encontra perdido, identificando o papel opositor de Ciro Gomes ao PT e demonstrando que o comentarista acompanha com atenção o futuro candidato à Presidência.

Discordando aqui presidente. Nós temos nojo dessa mundiça toda. Porém o sujeito é advogado e na época que defendeu esses criminosos estava só fazendo o trabalho dele. e Bem (Classificação "Ofício do advogado" e "Oposição a Bolsonaro", comentário, 22 maio 2020).

O governo está mostrando sua verdadeira face. Estamos à deriva desde o day after das eleições de 2014. Acredito que o único caminho é deixarmos as diferenças de lado e convergir no rumo da democracia (Classificação "Oposição a Bolsonaro", comentário, 22 maio 2020).

Ciro 2022 (Classificação “Oposição a Bolsonaro”, comentário, 22 maio 2020).

\section{Discussões}

Pelo exposto nas seções anteriores, percebemos como o nível de hostilidade a Marina entre seus comentaristas é alto. Todas as menções a ela com caráter negativo (que aparecem na Tabela 2, com exceção das missivas de apoio ao presidente), somadas, representam $51 \%$ do total de comentários, isto é, há um alto índice de agressão e rejeição à figura de Marina Silva. No caso de Ciro, a porcentagem dessas menções é de 16\%, e estão ligadas a tópicos como "Alcoolismo", "Caráter", "Cobrança" e "Atuação política". Somente as menções feitas pejorativamente à imagem corpórea de Marina somam $15 \%$ de todas as mensagens negativas. Não há nenhuma missiva pejorativa ligada à aparência de Ciro Gomes. Podemos constatar, portanto, que nesse caso há mais agressões à figura da mulher do que à do homem. 
É importante lembrar que Ciro tem, em seu histórico, episódios em que vídeos o registram alcoolizado (em um dos quais profere ataques verbais, com comentários de baixo calão), além de ele ser conhecido por ter emitido ataques explosivos a jornalistas e adversários. No entanto, há apenas uma menção pejorativa que se refere ao problema alcoólico e pouquíssimas referências a seu temperamento. O termo mais negativo usado contra ele é "coronel", referindo-se à figura que domina certas regiões interioranas do Nordeste, o que pode não ser necessariamente negativo, já que reafirma seus poder e virilidade.

Outro ponto foi o índice de comentaristas que percebem Marina como alguém ausente, desaparecida, sumida ou cancelada, com $13 \%$ dos comentários fazendo menções a isso, a despeito de ter presença constante em suas redes e de ter concedido muitas entrevistas em diversos veículos, especialmente no período pandêmico em que ocorreu a postagem. Inicialmente, levantamos a hipótese de que a dúvida do público em relação ao vigor da atuação política de Marina, em sua oposição ao governo de Jair Bolsonaro, deriva do fato de ela não ocupar cargo público no momento. No entanto, Ciro Gomes, que também faz oposição ao governo e tem sido tão atuante neste período quanto Marina, não foi mencionado por seus comentaristas como alguém que esteja sumido, ausente ou cancelado. Há $2 \%$ de menções que cobram ação por parte dele, como um pedido de que ele faça mais. Portanto, mais uma vez há percepção diferente, com respeito ao mesmo assunto, da figura da mulher com relação à do homem.

Por fim, as menções a Marina Silva com a expressão "múmia" (bem como referências ligadas a essa expressão) surpreenderam. A palavra "múmia", além de evocar algo assustador, por não ter vida, também traz os sentidos de esquálido, mirrado, esquelético, magro, por ser um cadáver preservado. Talvez nessa referência seja quando Marina é percebida de forma mais ligada à fragilidade corpórea.

Com relação às menções de apoio ao conteúdo postado por ambos, nota-se bastante diferença também. Ciro recebeu aprovação de sua fala em quase $70 \%$ do total de comentários em sua postagem, contra cerca de $30 \%$ no caso de Marina, ainda que as críticas colocadas em suas mensagens estejam em desacordo com as agendas ministeriais do atual governo, assim como as de Ciro. Um destaque em comum é que poucos interlocutores mencionam elogios ligados à competência, à liderança ou ao desempenho de Ciro ou Marina.

\section{Considerações Finais}

Na presente pesquisa, procuramos entender como Marina Silva, nortista, mulher e negra, e Ciro Gomes, nordestino, homem e branco, são percebidos pelo público através de suas redes sociais. Notou-se que ela é significativamente mais atacada e que há uma forte presença de estereótipos de gênero nesses comentários, ligando a mulher a ações políticas menos efetivas ou a padrões estéticos. Da mesma forma foi possível aferir, como declara Han (2017), que nas redes sociais percebemos pouco a alteridade que permite o diálogo entre os diferentes, e não a anulação, a invisibilidade e a hostilidade. Ou seja, a identificação dos sentidos dominantes nos comentários analisados revela a força de certas compreensões coletivas preconceituosas sobre a participação política feminina e das estratégias de silenciamento voltadas às mulheres. Isso corrobora a relevância dos estudos dos comentários presentes nas redes sociais pelo olhar da recepção, por ser mais uma forma de revelar estratégias de produção de sentido que se articulam a macroprocessos sociais - no caso, relacionados à construção social do gênero:

Partimos, portanto, do entendimento das redes como estratégias de interações sociais, espaços de intercâmbios flexíveis, dinâmicos e em constante movimento, que não deixam de comportar relações de poder expressas nas disputas, hierarquias e assimetrias que constituem a esfera da comunicação e da cultura. (Cogo \& Brignol, 2011, p. 82)

Além disso, os discursos que veiculam ataques a sua aparência sugerem desumanização de sua figura, trazendo um outro questionamento: a cor de sua pele seria um fato provocador dessa visão? Assim, nos parece essencial entender 
sexismo e racismo como elementos inseparáveis, como afirma Hooks (2019). Não é possível olhar para Marina apenas pela questão machista ou pela racial para entender por que ela é atacada de forma desumanizada. Portanto, o campo do feminismo e suas interseccionalidades é fundamental para compreender esse fenômeno que se desenha aqui. É o que pretendemos realizar na continuidade deste trabalho.

\section{Referências}

BARDIN, L. (2002). Análise de conteúdo. Edições 70.

CANCLINI, N. G. (2004). Diferentes, desiguales y desconectados: mapas de interculturalidade. Gedisa.

CASTELLS, M. (1999). A sociedade em rede. Paz e Terra.

COGO, D., \& BRIGNOL, L. D. (2011). Redes sociais e os estudos de recepção na internet. MATRIZes, 4 (2), 75-92, http://doi.org/10.11606/issn.1982-8160.v4i2p75-92.

ESCOSTEGUY, A. C. D. (2002). Os estudos de recepção e as relações de gênero: algumas anotações provisórias. Ciber legenda, 1 (7), https://periodicos.uff.br/ ciberlegenda/article/view/36797.

FINAMORE, C. M., \& CARVALHO, J. E. C. (2006). Mulheres candidatas: relações entre gênero, mídia e discurso. Estudos Feministas, 14 (2), 347-362, https://doi. org/10.1590/S0104-026X2006000200002.

FURTADO, T., \& DORETTO, J. (2019). The "young black man" in the photo: the production of meaning in reader comments from the El País Newspaper. Brazilian Journalism Research, 15 (1), 148-175, https://doi.org/10.25200/BJR. v15n1.2019.1149.

HALL, S. (2003). Da diáspora: identidades de mediações culturais. Editora UFMG.

HAN, B.-C. (2017). Sociedade do cansaço. Vozes.

HOOKS, B. (2019). E eu não sou uma mulher? Rosa dos Tempos.

MORIN. E. (2007). Cultura de massas no século XX. Volume 1: Neurose. Forense Universitária.

PAINS, C. (2018, 7 de março). Brasil tem menos parlamentares mulheres do que 151 países. O Globo On-line. https://oglobo.globo.com/sociedade/brasil-temmenos-parlamentares-mulheres-do-que-151-paises-22462336.

SCHUMAHER, S, \& CEVA, A. (2015). Mulheres no poder: trajetórias na política a partir da luta das sufragistas do Brasil. Edições de Janeiro.

SOUSA, M. W. (1994). Recepção e comunicação: a busca do sujeito. In M. W. Sousa (Org.), Sujeito, o lado oculto do receptor (pp. 13-38), Brasiliense. 